\title{
Motivating Employees Creativity through Suggestion System - An Empirical Study
}

\author{
Mrs.S.Vijayarani ${ }^{1}$, Dr.Radjamanogary ${ }^{2}$ \\ 1. Assistant Professor (OG), Department of Management studies, SRM University, Ramapuram, Chennai - 87, \\ India. \\ 2. Dr.Radjamanogary, Associate Professor, Department of Management studies, St.Joseph's Engineering \\ College, Chennai, India.
}

\begin{abstract}
Employees are treated as assets in the organization. In a competitive business environment, one of the key elements of an organization success is their employees' intellectual capability to improve the organizational performance by way of reducing cost, new product development, generate new ideas related to product, process and other areas of management. The employees are find novel ideas and proposed these ideas to management through suggestion system. Suggestion system is technique which is motivating the employees to participate in decision making process and improve the organization performance.The primary data was collected through structure questionnaire based on convenience sampling method. This research paper focus on employee creativity and its impact on suggestion system and the aims of this article are to find an answer for two questions: 1. what are the factors motivating employee creativity? and 2. What is the impact of creativity on employee suggestion system? Finally this article conclude that both organizational factors and individual factors influencing creativity and there is a positive relationship between employee creativity and suggestion system.
\end{abstract}

Key words: Creativity, Motivation, Recognition, Reward system suggestion scheme.

\section{Introduction}

Creativity is an internal and intellectual process of bringing about new ideas (Koontz et al., 1980). Organizations are required to be creative and innovative to the extent that their environment is unpredictable, unstable or threatening (Roni Reiter-Palmon, Jody J. Illies, 2004). In a turbulent environments, heightened competition, and unpredictable technological change, more and more managers are coming to realize that they should encourage their employees to be creative (Shalley \& Gilson, 2004). Researchers have suggested that creativity - the generation of novel and useful ideas (Amabile, 1988, 1996). If the employees are treated as a part of organization effort, then they are much interested to contribute more ideas to the organization. Organizational and supervisory factors are effective in motivating employee to participate in environmental innovations that can increase the sustainability (Ceres, 1995). Hence it is the obligation of a top management and leaders to motivate and nurture their employee's creativity.

The company must understanding the behavior of the employees and creates a culture to drive employee's creativity in the organization. Suggestion systems can be a useful way to obtain and utilize employees' creative ideas; effective suggestion management systems must also motivate employees to think creatively and to participate in the suggestion process (James Fairbank, Spangler, Scott, 2003). Innovative companies carefully analyze personnel needs and hire creative people to fulfill organizational goals; they must implement reward systems to recognize and boost employee creativity. (Gupta, A.K. \& Singhal, A., 1993.) Creativity is an important key factor for IT Industry in a competitive market. Over a decade's, Information Technology (IT) has grown to become an indispensable part of our life. Employee creativity is an essential parameter, in order to grow and survive in the Global competitive market for Information and Technology companies. Customers are constantly seeking new and innovative solutions from IT companies to make their job easier and more entertaining, on the other side, companies have incorporated IT into their way of doing is business need to beat their competitors and lead the market through digital revolution in day- to-day business. Survival in the IT-industry is based on the ability of the company to explore different types of solutions to a given problem using creativity and implement this through employee suggestion system and value adding innovative solution is therefore a valuable asset which can lead to competitive advantages. The main purpose of this empirical paper is to present a general approach to assess the employee creativity and its effect on suggestion system in IT companies. 


\section{Objectives Of The Study}

The aim of this research paper is to find out the effect of employee creativity on suggestion system. The objectives are:

1. To identify the factors that motivating employee creativity

2. To study different motivational techniques of suggestion system

3. To analyze the effect of employee creativity on suggestion scheme.

\section{Review Of Literature And Background Of The Study}

Employee suggestion systems are a useful way to obtain and utilize employees' creative ideas; to be effective; employees must be motivated to think creatively and to participate in the suggestion system (Fairbank, J. F. and Williams, S. D., 2001). Ideas are derived not only from people of above average intelligence, but also from those of average intelligence (Simon Wong, Loretta Pang, 2003). The most significant factors influencing the creativity of the people are organizational factors (Reza, Elaheh Hasanzadeh, 2010). Organizational factors encompass leadership style (Jannat Poor, 2000), organizations culture (Lioyd, 1996), organizational structure (McAdam and McClelland, 2002), reward system (Farhang, 1998).

The generation of ideas has to be organized and initiated by the senior management of an organization (Cindy Wu, Jeffery S. McMullen, Mitchell J. Neubert, Xiang Yi, 2008). Leadership is an important aspect of the work environment for employee's creativity. (Oldham \& Cummings, 1996; Scott \& Bruce, 1994). Nowadays many companies are aware of the importance of employee creativity; Suggestion systems are among the instruments for channeling creativity (Van Dijk, C. and Van Den Ende, J., 2002). It is the responsibility of a leader to identify the capable employees and motivate them to submit more creative ideas. However, for employees with a high identification with leader, the relationship between transformational leadership and employee creativity was stronger under high innovative climate than it was under low innovative climate (Wang \& Rode, 2010). The responsibility of implementing the approved suggestions lies with the middle/junior managers. They should coach, guide and encourage creativity and empowerment. Other most important factors influencing the creativity of people are individual factors. Individual factors include self-confidence, accepting ambiguities (skepticism), patience, holistic attitude, curiosity (Jannat Poor, 2000). Creativity is the personal characteristics and intellectual abilities of individuals and still others focus on the product with regard to the different qualities and outcomes of creative attempts (Arad et al., 1997; Udwadia, 1990).

Suggestion system is a technique that will motivate the employees to think creatively and to participate in the decision making process. Motivating employees involves more than simply offering rewards to submitters if their suggestions are put to use; According to expectancy theory, rewards will only motivate behaviour, if the rewards are valued (Fairbank, J. F. and Williams, S. D., 2001). Intrinsic job-related motivators which include opportunity for advancement and development, loyalty to employees, appreciation and praise of work done, feelings of being involved, sympathetic help with personal problems and interesting work, are found to encourage the employees' risk-taking behavior (Ricardo Recht, Celeste Wilderom, 1998). Employees with highly specialized knowledge, who bring new ideas and experiences, should be recognized and rewarded to make knowledge sharing a reality in the organization that supports innovation (Popadiuk, Choo, 2006, Pluskowski, 2002). Initiative and creativity need to be come up with good ideas and to write up these ideas in a suggestion. (Michael frees, Eric Teng and Cees J.D Wijnen , 1999)

The suggestion scheme motivates employees to use their experience, expertise and creativity to improve the way the business is run (Abdel Moniem ,Ahmed Huda Buhmaid ). Staff suggestion scheme is a formalized procedure to encourage the employees to think creatively about their jobs and their job environment and to come forward with ideas for which they will be rewarded on a specific basis, if acceptable and to the advantage of the organization (Andrew E. Marx, 1993). Techniques to motivate empower and reward staff become ever more sophisticated and expensive, one of the most obvious, though overlooked; ways of tapping the creativity of employees is the suggestion scheme (Geoffrey C. Lloyd, 1996)

The humble suggestion scheme can be a creative resource and a springboard for transforming an organization; Takes a novel, situation-based look at creativity and, with a mix of theory and pragmatism, outlines a strategy for encouraging and directing creativity for organizational good and individual reward (Dean Junipe, 1996).

\subsection{Sampling Techniques and Data collection Method:}

\section{Research Methodology}

The sample was drawn from IT companies. The survey was conducted over 236 employees based on convenience sampling techniques. The primary data was collected through structure questionnaire and the questionnaire has two sections which include personal information and questions related to research objectives. The secondary sources of data were collected from internet and libraries. 


\subsection{Measurement}

After detailed review of literature some important variables are identified and detail study was made on each variables. Based on the research objectives the variables are classified and test the relationship between variables using statistical tools. The questionnaire consists of one central variable (Suggestion system), one dependent variable (employee creativity) and one independent variable (motivation).

\subsection{Data collection}

The sources of data collections are primary data and secondary data. The primary data was collected through structured questionnaire and the secondary data was collected from journals, internet ect.,

\subsection{Analysis and Interpretation}

Table - 4.4.1

Age and Gender of the respondents

\begin{tabular}{|c|c|c|c|c|}
\hline Sl.No & \multicolumn{2}{|c|}{ Demographic factor } & No. of Respondents & Respondents in \% \\
\hline \multirow[t]{4}{*}{1} & \multirow{4}{*}{ Age } & Less than 25 years & 65 & 28 \\
\hline & & $25-35$ years & 91 & 39 \\
\hline & & $35-45$ years & 46 & 19 \\
\hline & & Above 45 years & 34 & 14 \\
\hline \multirow[t]{2}{*}{3} & \multirow[t]{2}{*}{ Gender } & Male & 149 & 63 \\
\hline & & Female & 87 & 37 \\
\hline
\end{tabular}

Inference: From the above table $39 \%$ of the respondents are the age group between $25-35$ years and $28 \%$ of the respondents are less than 25 years, $63 \%$ of the respondents are males and $37 \%$ of the respondents are female.

Table -4.4 .2$

Factors motivating employee creativity

\begin{tabular}{|c|c|c|c|c|c|c|}
\hline Sl.No & Factors & SA & $\mathbf{A}$ & $\mathbf{N}$ & DA & SDA \\
\hline \multirow[t]{2}{*}{1} & \multirow[t]{2}{*}{ Recognition } & 93 & 75 & 31 & 28 & 9 \\
\hline & & $39 \%$ & $32 \%$ & $13 \%$ & $12 \%$ & $4 \%$ \\
\hline \multirow[t]{2}{*}{2} & \multirow{2}{*}{ Job advancement and development } & 85 & 67 & 29 & 31 & 24 \\
\hline & & $36 \%$ & $28 \%$ & $12 \%$ & $13 \%$ & $2 \%$ \\
\hline \multirow[t]{2}{*}{3} & \multirow[t]{2}{*}{ Rewards } & 113 & 79 & 16 & 11 & 17 \\
\hline & & $48 \%$ & $33 \%$ & $77 \%$ & $5 \%$ & $7 \%$ \\
\hline \multirow[t]{2}{*}{4} & \multirow[t]{2}{*}{ Leadership style } & 91 & 83 & 28 & 16 & 18 \\
\hline & & $39 \%$ & $35 \%$ & $12 \%$ & $77 \%$ & $8 \%$ \\
\hline \multirow[t]{2}{*}{5} & \multirow[t]{2}{*}{ Organization culture and structure } & 107 & 85 & 19 & 17 & 8 \\
\hline & & $45 \%$ & $36 \%$ & $8 \%$ & $7 \%$ & $3 \%$ \\
\hline
\end{tabular}

Chart - 4.4.1

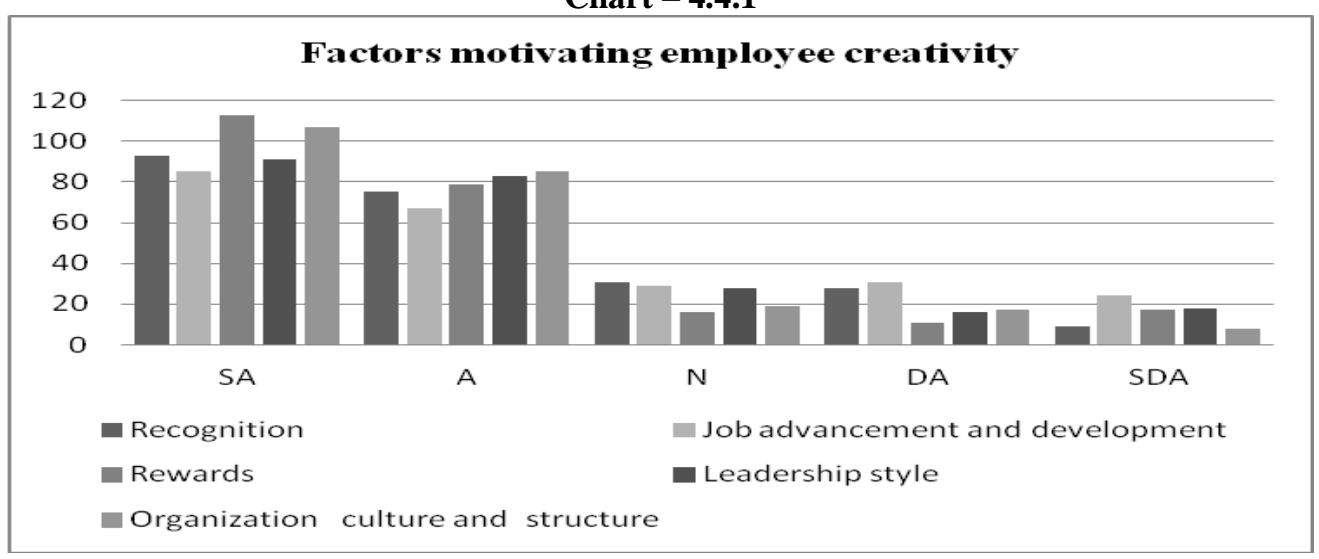

Inference:

From the above table $48 \%$ of the respondents strongly agree that Rewards motivate to think new ideas, and only $2 \%$ of the respondents strongly disagree that Job advancement and development does not motivate creativity. 
Table - 4.4.3

Motivational techniques for employee creativity

\begin{tabular}{|c|c|c|c|c|c|c|}
\hline Sl.No & Factors & SA & $\mathbf{A}$ & $\mathbf{N}$ & DA & SDA \\
\hline \multirow[t]{2}{*}{1} & \multirow[t]{2}{*}{ Monetary rewards } & 102 & 96 & 15 & 11 & 12 \\
\hline & & $43 \%$ & $41 \%$ & $6 \%$ & $5 \%$ & $3 \%$ \\
\hline \multirow[t]{2}{*}{2} & \multirow[t]{2}{*}{ Non-monetary rewards } & 88 & 65 & 19 & 38 & 26 \\
\hline & & $37 \%$ & $28 \%$ & $8 \%$ & $16 \%$ & $7 \%$ \\
\hline \multirow[t]{2}{*}{3} & \multirow[t]{2}{*}{ Recognition } & 109 & 87 & 11 & 24 & 5 \\
\hline & & $46 \%$ & $37 \%$ & $5 \%$ & $10 \%$ & $2 \%$ \\
\hline \multirow[t]{2}{*}{4} & \multirow{2}{*}{$\begin{array}{l}\text { Motivated by colleagues to create new } \\
\text { ideas }\end{array}$} & 92 & 79 & 29 & 19 & 17 \\
\hline & & $39 \%$ & $33 \%$ & $2 \%$ & $8 \%$ & $7 \%$ \\
\hline \multirow[t]{2}{*}{5} & \multirow{2}{*}{$\begin{array}{l}\text { encouraged by managers/ supervisors } \\
\text { to be creative in my job }\end{array}$} & 104 & 97 & 9 & 15 & 11 \\
\hline & & $44 \%$ & $41 \%$ & $4 \%$ & $6 \%$ & $5 \%$ \\
\hline
\end{tabular}

Chart 4.4.2

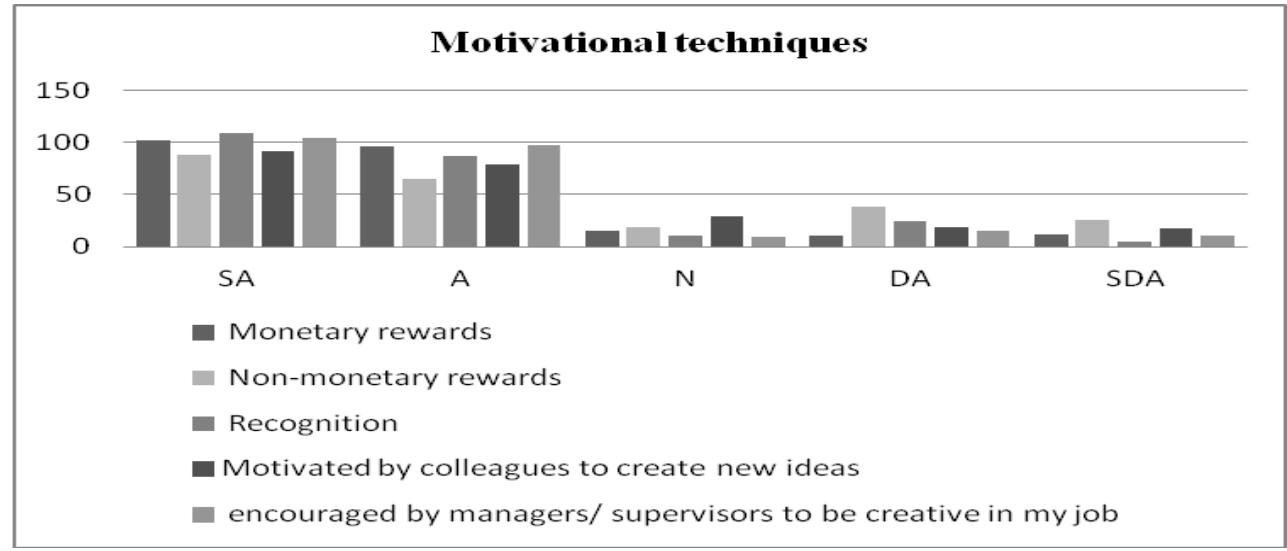

Interpretation:

The table indicate that $46 \%$ of the respondents are strongly agree, that they are motivated by recognition and $2 \%$ of the respondents are neutral that they are motivated by colleagues.

Table - 4.4.4

Improve Employee creativity through suggestion system

\begin{tabular}{|l|l|l|l|l|l|l|}
\hline Sl.No & Employee opinion & SA & A & N & D & SDA \\
\hline 1 & $\begin{array}{l}\text { I would suggest more ideas if my organization culture } \\
\text { support employee creativity }\end{array}$ & 115 & 79 & 16 & 11 & 14 \\
\cline { 5 - 7 } & $49 \%$ & $33 \%$ & $7 \%$ & $5 \%$ & $6 \%$ \\
\hline 2 & $\begin{array}{l}\text { Training on creativity helps me to participate in } \\
\text { suggestion system }\end{array}$ & 107 & 93 & 13 & 11 & 12 \\
\cline { 3 - 7 } & $\begin{array}{l}\text { Brainstorming session is available in my organization } \\
\text { to generating and developing new ideas }\end{array}$ & 91 & 67 & 29 & 25 & 24 \\
\cline { 3 - 7 } & $\begin{array}{l}\text { Through my creative skill frequently I can offer more } \\
\text { suggestion to the organization. }\end{array}$ & 103 & 95 & 10 & 15 & 13 \\
\cline { 3 - 7 } & & $44 \%$ & $40 \%$ & $4 \%$ & $6 \%$ & $6 \%$ \\
\hline
\end{tabular}

\section{Interpretation:}

The table indicate that $49 \%$ of the respondents are strongly agree, with the statement that they suggest more ideas if my organization culture support creativity. $4 \%$ of the respondents are neutral, that through suggestion system they can improve their creative skill.

\subsection{Statistical Analysis:}

\subsubsection{Independent Sample t- test}

Ho: There is no relationship between Gender of the respondents and Motivation by recognition H1: There is a relationship between Gender of the respondents and motivation by recognition 
Table 4.5.1

Independent Samples Test

\begin{tabular}{|c|c|c|c|c|c|c|c|c|c|c|}
\hline & \multicolumn{2}{|c|}{$\begin{array}{l}\text { Levene's Test } \\
\text { for Equality } \\
\text { of Variances }\end{array}$} & \multicolumn{7}{|c|}{ t-test for Equality of Means } \\
\hline & & \multirow[b]{2}{*}{$\mathrm{F}$} & \multirow[b]{2}{*}{ Sig. } & \multirow[b]{2}{*}{$\mathrm{t}$} & \multirow[b]{2}{*}{$\mathrm{df}$} & \multirow{2}{*}{$\begin{array}{l}\text { Sig. (2- } \\
\text { tailed) }\end{array}$} & \multirow{2}{*}{\begin{tabular}{|c} 
Mean \\
Differenc \\
e \\
\end{tabular}} & \multirow{2}{*}{$\begin{array}{c}\text { Std. Error } \\
\text { Differenc } \\
\mathrm{e}\end{array}$} & \multicolumn{2}{|c|}{$\begin{array}{l}\text { 95\% Confidence } \\
\text { Interval of the } \\
\text { Difference }\end{array}$} \\
\hline & & & & & & & & & Lower & Upper \\
\hline $\begin{array}{l}\text { Recogniti } \\
\text { on }\end{array}$ & $\begin{array}{l}\text { Equal } \\
\text { variances } \\
\text { assumed }\end{array}$ & 2.432 & .120 & -.641 & 234 & .522 & -.089 & .139 & -.362 & .184 \\
\hline & $\begin{array}{l}\text { Equal } \\
\text { variances } \\
\text { not } \\
\text { assumed }\end{array}$ & & & -679 & 211.5 & .498 & -.089 & .131 & -.347 & .169 \\
\hline
\end{tabular}

The significance value from the above table is $0.498>0.05$, so the null hypothesis is accepted.

Result: There is no relationship between the gender of the respondents and motivation by recognition.

\subsubsection{Two - way ANOVA}

$\mathrm{H}_{0}$ : There is no relationship between Age and Gender of the respondents and preference of monetary rewards $\mathrm{H}_{1}$ : There is a relationship between age and gender of the respondents and preference of monetary rewards

Table - 4.4.2

\section{Tests of Between-Subjects Effects}

Dependent Variable: Preference of Monetary Rewards

\begin{tabular}{|l|r|r|r|r|r|}
\hline Source & $\begin{array}{c}\text { Type III Sum of } \\
\text { Squares }\end{array}$ & df & Mean Square & F & \multicolumn{1}{c|}{ Sig. } \\
\hline Corrected Model & $10.139^{\mathrm{a}}$ & 7 & 1.448 & 1.282 & .260 \\
Intercept & 3385.150 & 1 & 3385.150 & $2.997 \mathrm{E} 3$ & .000 \\
Gender & .092 & 1 & .092 & .081 & .776 \\
Age & 2.210 & 3 & .737 & .652 & .582 \\
Gender * age & 8.906 & 3 & 2.969 & 2.628 & .051 \\
Error & 257.522 & 228 & 1.129 & & \\
Total & 4304.000 & 236 & & & \\
Corrected Total & 267.661 & 235 & & & \\
\hline
\end{tabular}

a. $\mathrm{R}$ Squared $=.038$ (Adjusted R Squared $=.008$ )

The significance value $0.260>0.05$, so the null hypothesis is accepted.

Result: The Age and Gender of the respondents does not influence the preference of monetary rewards.

\section{Result And Discussion}

Based on the analysis $39 \%$ of the respondents are the age group between $25-35$ years and $28 \%$ of the respondents are less than 25 years, $63 \%$ of the respondents are males and $37 \%$ of the respondents are female, $48 \%$ of the respondents strongly agree that Rewards motivate to think new ideas, and only $2 \%$ of the respondents strongly disagree that Job advancement and development does not motivate creativity. The table indicate that $46 \%$ of the respondents are strongly agree, that they are motivated by recognition and $2 \%$ of the respondents are neutral that they are motivated by colleague The table indicate that $49 \%$ of the respondents are 
strongly agree, with the statement that they suggest more ideas if my organization culture support creativity. $4 \%$ of the respondents are neutral, that through suggestion system they can improve their creative skill. It is evidence that most of the respondents are agreed that there is a positive effect between employee creativity and suggestion system.

After detail analysis, the relationships between variables are analyzed and hypothesis was tested. Based on the statistical analysis, both the analysis was accepting the null hypothesis. The Age and Gender of the respondents are influenced the preference of monetary rewards and the gender of the respondents does not influenced recognition as a motivational techniques.

\section{Conclusion}

In a modern business scenario survival of a company is depends upon advancement in their business. Creativity playing a vital role to be innovative and improve the performance of an organization .There is lot of techniques, methods and systems, used by the company for increasing their profit, growth and advancement in a competitive market. This study has mentioned that suggestion system is a technique which improves employee creativity. The importance of employee creativity in the firm helps to encourage the suggestion systems and improve the performance of an organization.

\section{References}

[1]. A Nijhof, K Krabbendam, J.C Looise (2002), Innovation through exemptions: building upon the existing creativity of employees , Technovation, Volume 22, Issue 11, 2002, Pages675-683

[2]. Andrew E. Marx (1995) Management commitment for successful suggestion systems Work Study Volume: 44 Issue: 3

[3]. Ceres, (1995), Guide to Ceres principles, coalition for environmentally responsible economies.

[4]. Cindy Wu, McMullen, Mitchell J. Neubert, Xiang Yi (2008), The influence of leader regulatory focus on employee creativity, Journal of Business Venturing, Volume 23, Issue 5, Pages Fairbank, J. F. and Williams, S. D. (2001), Motivating Creativity and Enhancing Innovation through Employee Suggestion System Technology. Creativity and Innovation Management, Vol -10, pp:68-74.

[5]. Gupta, A.K. \& Singhal, A., (1993). Managing Human-Resources for Innovation and Creativity. ResearchTechnology Management, Vol: 36 Issue:3, p.41-48

[6]. James Fairbank, William Spangler, Scott David Williams, (2003), Motivating creativity through a computer-mediated employee suggestion management system Behaviour \& Information Technology Vol. 22, Issue:5.

[7]. Jing Zhou, Jennifer M. George (2003) Awakening employee creativity: The role of leader emotional intelligence The Leadership Quarterly, Volume $\quad 14, \quad$ Issues $\quad 4-5, \quad$ Pages Michael frese1, Eric teng and Cees J. D. Wijne(1999), Helping to improve suggestion systems: predictors of making suggestions in companies, Journal of Organizational Behavior, Vol:20, $1139-1155$

[8]. Popadiuk, S. and Choo, W.C. (2006), Innovation and knowledge creation: How are these concepts related?", International Journal of Information Management, Vol. 26 pp. 302-312.

[9]. Reza , Hasanzadeh,(2010) Factors Influencing Creativity and Innovation of the Senior Managers of Iran University of Medical Sciences, Research Journal of Biological Sciences, Vol:5, Issue:11, pp: 708 -712

[10]. Ricardo Recht, Celeste Wilderom (1998) Kaizen and culture: on the transferability of Japanese suggestion systems, International Business Review, Volume $\quad$ Issue Roni Reiter-Palmon, Jody J. Illies (2004) Leadership and creativity: Understanding leadership from a creative problem-solving perspective, The Leadership Quarterly, Volume 15, Issue 1, , Pages 55-77 Simon Wong, Loretta Pang (2003), Motivators to creativity in the hotel industry—perspectives of managers and supervisors Tourism Management, Volume 24, Issue 5, Pages 551-559

[11]. S.Wong(2008),Exploring the relationship between employee creativity and job-related motivators in the Hong Kong hotel industry International Journal of Hospitality Management, Volume 27, Issue 3, Pages 426-437

[12]. Van Dijk, C. and Van Den Ende, J. (2002), Suggestion systems: transferring employee creativity into practicable ideas. R\&D Management, Vol- 32, pp: 387-395.

[13]. Wang, P., \& Rode, J.C. (2010).Transformational leadership and follower creativity: The moderating effects of identification with leader and organizational climate. Human Relations Vol:24, Issue:1

Reference from working paper:

[14]. Critical factors for a successful implementation of a staff suggestion scheme By Dr Abdel Moniem Ahmed Huda Buhmaid (WP0102052007)

\section{Reference from Website:}

a. www.google.com

b. www.emeraldinsight.com

c. www.sciencedirect.com 